\title{
Expanding the boundaries of point of care testing
}

\author{
Thomas J. Morgan ${ }^{1}$. Christopher M. Anstey ${ }^{2,3}$
}

Received: 26 June 2019 / Accepted: 26 June 2019 / Published online: 28 June 2019

(c) Springer Nature B.V. 2019

Point of care (POC) or 'near patient' testing refers to testing and reporting at the site of patient care, usually by nonlaboratory or where applicable by non-imaging personnel. Although now a growth industry, the POC concept is not new. Modalities brought to the bedside in decades past have included ultrasonography [1], echocardiography [2], pulse oximetry [3], and intra-arterial [4] and transcutaneous [5] as well as benchtop blood gas monitoring. Current applications are legion, whether wearable, hand-held or benchtop devices [6]. To cite just a few we have glycosylated haemoglobin analysis [7], pulse co-oximetry [8], thrombo-elastography [9], therapeutic drug and drugs of abuse screening [10], tests for malaria, tubercle bacillus and the dengue virus [11] and cartridge-based analysers offering suites of tests such as blood gas analysis, electrolyte and urea/creatinine panels, haematocrit and coagulation testing, rapid cardiac markers and $\beta$-HCG assays $[12,13]$.

Clear evidence that POC testing improves outcomes is lacking, although there have been attempts [14, 15]. Field hospital deployment in zones of conflict and natural disasters are applications with likely benefits, and emerging health care systems in developing countries offer great potential for POC devices if regulated appropriately. By the same token their convenience, rapid turn-around and consequent enhanced clinical decision-making have accelerated takeup of POC testing in established health care systems. Paramedics attending multi-trauma victims can measure International Normalized Ratio (INR) values on-site to trigger

Thomas J. Morgan

t.morgan@uq.edu.au

Christopher M. Anstey

chris.anstey@health.qld.gov.au

1 Intensive Care Unit, Mater Research - University of Queensland, Mater Health Services, Stanley Street, South Brisbane, QLD 4101, Australia

2 Department of Intensive Care, Sunshine Coast Hospital, Nambour, QLD 4560, Australia

3 The University of Queensland, Brisbane, QLD 4101, Australia pre-hospital blood product administration [16]. Long-haul retrieval teams carry cartridge-based analysers with wideranging testing capabilities for use on patients both pre-flight and in the air (J Pincus, personal communication). General practitioners are seeking to expand the role of POC testing in their practices $[17,18]$.

Within hospitals POC devices are encountered in emergency rooms, operating rooms and intensive care units, typically networked with a core laboratory and administered within its regulatory umbrella. The international standards ISO 22870 and ISO 15189 mandate quality management systems for POC devices, with scheduled Quality Control testing plus cyclic External Quality Assessment benchmarked against large user databases. Core laboratories are at the centre of these 'hub and spoke' models, ensuring that POC devices and their users comply with regulatory requirements. Published guidelines for POC testing in clinical chemistry deal with governance, compliance with accreditation standards, training of operating personnel, connectivity, laboratory oversight and device selection [19-21].

On this background Dr Sarraf and colleagues at the University of Vermont College of Medicine have ventured beyond the normal job description of a common category of POC analyser, the type whose output 'forms a continuum' [22]. Their focus is on the potential for these devices to act as screening tools for tests which define a binary outcome. To this end the authors have designed what is essentially an operating framework to maximize cost-efficiency and safety when used for this purpose. The example given is testing INR values on day of surgery in a patient population with a potential coagulopathy, where a laboratory value $\geq 1.5$ would mean deferral of the procedure for safety considerations.

Their approach hinges on data drawn from parallel testing of POC devices and their formal laboratory equivalents. In simple terms and using the example given, a POC INR value of 1.7 may turn out from parallel testing data to be the lowest POC INR which almost guarantees that the 'true' laboratory INR $\geq 1.5$. In other words, at POC INR $\geq 1.7$ false positives for a high laboratory INR are extremely unlikely, 
or in statistical terms specificity for an unacceptable laboratory INR (true negatives/[true negatives + false positives]) is close to 1.0. That being so, when the POC device reports an INR $\geq 1.7$ no further testing is required and the invasive procedure is deferred. The likelihood that patients in this group could experience inappropriate cancellations is small.

For the same POC device it might also turn out that a value of 1.3 is the highest POC INR which almost guarantees that the 'true' INR is $<1.5$. In other words, false positives for an INR $<1.5$ are again extremely unlikely at this threshold, and specificity for a safe laboratory INR is close to 1.0. That being so, when the POC device reports an INR $\leq 1.3$ no further testing is required and the surgery is allowed to proceed. From the clinician standpoint, the likelihood that patients in this group could still undergo surgery whilst having an unsafe laboratory INR is small indeed.

However, if the POC INR lies in the 'grey area', which in this theoretical example would be 1.4 to 1.6 , formal laboratory testing with its delay and additional expense must be undergone before a final decision is reached. False positives in either category which could lead to inappropriate clinical decisions are then eliminated. In such a framework the breadth of the grey area and the characteristics of the population being tested have critical influences on whether an economic analysis would favour POC screening with laboratory back-up or universal laboratory testing.

This seemingly intuitive approach is explored in much more detail by Dr Sarraf and colleagues [22], although with some difference in terminology. For example, the authors describe the lower POC threshold as the 'sensitivity_threshold' for a clinically unsafe true INR, whereas we have described it above as a specificity threshold for a safe laboratory INR. Apart from a review of the statistical principles involved, the authors detail how to perform an economic analysis of POC screening versus universal laboratory testing, emphasizing that all factors such as user training should be included. They also provide a simulation of two POC devices screening 9320 real day of surgery 'true' INR values via published algorithms derived from parallel testing [23, 24]. 'True' INR cut-offs of 1.5 and 1.8 are modelled, first with the whole population and then with skewed datasets created by depleting higher or lower INR sub-groups. Finally they refer to potential regulatory barriers to the marketing of POC devices for this purpose.

For one of the devices [23] the investigators found that only $9 \%$ of the population POC-tested at $99.5 \%$ sensitivity for a 'true' INR $\geq 1.5$ would require formal laboratory testing. They emphasize that clinician intolerance of risk is critical to the selection of thresholds, which define the breadth of the grey area and have consequent economic impact. For a clinician the dominant risk and major focus in the example given would be that of performing an invasive procedure on a coagulopathic patient. As Dr Sarraf and colleagues point out, clinicians performing surgery and other invasive procedures would not be comfortable with $95 \%$ sensitivity in detecting an unacceptable coagulopathy pre-procedure, since there would still be a $5 \%$ chance of preventable bleeding with all the associated morbidity and mortality connotations. On the other hand, there is no doubt that unnecessary procedure deferral is also undesirable, with adverse economic impacts and potential negative effects on patient well-being especially if urgent procedures are incorrectly postponed. However in the main there would be reduced likelihood of major clinical detriment.

One final comment relates to the clinician mind-set which naturally favours formal laboratory results over POC. The concepts advanced by Dr Sarraf and colleagues operate within this construct. Although this is largely appropriate, the exact opposite can apply on occasion. For example, we regard direct ion selective electrode (ISE) measurements as preferable to laboratory indirect ISE measurements when tracking plasma sodium concentrations, even if generated by (trained) non-laboratory personnel on a POC device in an intensive care unit, despite the vicissitudes of that chaotic clinical environment [25].

\section{References}

1. Buerger AM, Clark KR. Point-of-care ultrasound: a trend in health care. Radiol Technol. 2017;89(2):127-38.

2. Krishnamoorthy VK, Sengupta PP, Gentile F, Khandheria BK. History of echocardiography and its future applications in medicine. Crit Care Med. 2007;35(8 Suppl):S309-13. https://doi. org/10.1097/01.CCM.0000270240.97375.DE.

3. McMorrow RC, Mythen MG. Pulse oximetry. Curr Opin Crit Care. 2006;12(3):269-71. https://doi.org/10.1097/01.ccx.00002 24873.16700.78.

4. Venkatesh B, Hendry SP. Continuous intra-arterial blood gas monitoring. Intensive Care Med. 1996;22(8):818-28.

5. Storre JH, Magnet FS, Dreher M, Windisch W. Transcutaneous monitoring as a replacement for arterial $\mathrm{PCO}(2)$ monitoring during nocturnal non-invasive ventilation. Respir Med. 2011;105(1):143-50. https://doi.org/10.1016/j.rmed.2010.10.007.

6. Nayak S, Blumenfeld NR, Laksanasopin T, Sia SK. Point-of-Care diagnostics: recent developments in a connected age. Anal Chem. 2017;89(1):102-23. https://doi.org/10.1021/acs.analchem.6b046 30.

7. Pluddemann A, Price CP, Thompson M, Wolstenholme J, Heneghan C. Primary care diagnostic technology update: pointof-care testing for glycosylated haemoglobin. Br J Gen Pract. 2011;61(583):139-40. https://doi.org/10.3399/bjgp11X556290.

8. Welker E, Novak J, Jelsma L, Koehler T, Davis A, DeCou J, Durkin E. Continuous hemoglobin monitoring in pediatric trauma patients with solid organ injury. J Pediatr Surg. 2018;53(10):20558. https://doi.org/10.1016/j.jpedsurg.2017.12.015.

9. Deppe AC, Weber C, Zimmermann J, Kuhn EW, Slottosch I, Liakopoulos OJ, Choi YH, Wahlers T. Point-of-care thromboelastography/thromboelastometry-based coagulation management in cardiac surgery: a meta-analysis of 8332 patients. J Surg Res. 2016;203(2):424-33. https://doi.org/10.1016/j.jss.2016.03.008. 
10. Attema-de Jonge ME, Peeters SY, Franssen EJ. Performance of three point-of-care urinalysis test devices for drugs of abuse and therapeutic drugs applied in the emergency department. J Emerg Med. 2012;42(6):682-91. https://doi.org/10.1016/j.jemer med.2011.01.031.

11. Drancourt M, Michel-Lepage A, Boyer S, Raoult D. The pointof-care laboratory in clinical microbiology. Clin Microbiol Rev. 2016;29(3):429-47. https://doi.org/10.1128/CMR.00090-15.

12. Martin CL. i-STAT - combining chemistry and haematology in PoCT. Clin Biochem Rev. 2010;31(3):81-4.

13. Wilgen U, Pretorius CJ, Gous RS, Martin C, Hale VJ, Ungerer JP. Hook effect in Abbott i-STAT beta-human chorionic gonadotropin (beta-hCG) point of care assay. Clin Biochem. 2014;47(1314):1320-2. https://doi.org/10.1016/j.clinbiochem.2014.05.005.

14. Rossi AF, Khan DM, Hannan R, Bolivar J, Zaidenweber M, Burke R. Goal-directed medical therapy and point-of-care testing improve outcomes after congenital heart surgery. Intensive Care Med. 2005;31(1):98-104. https://doi.org/10.1007/s0013 4-004-2504-1.

15. Laffel LM, Wentzell K, Loughlin C, Tovar A, Moltz K, Brink S. Sick day management using blood 3-hydroxybutyrate (3-OHB) compared with urine ketone monitoring reduces hospital visits in young people with T1DM: a randomized clinical trial. Diabet Med. 2006;23(3):278-84. https://doi.org/10.111 1/j.1464-5491.2005.01771.x.

16. Beynon C, Erk AG, Potzy A, Mohr S, Popp E. Point of care coagulometry in prehospital emergency care: an observational study. Scand J Trauma Resusc Emerg Med. 2015;23:58. https://doi. org/10.1186/s13049-015-0139-6.

17. Turner PJ, Van den Bruel A, Jones CH, Pluddemann A, Heneghan C, Thompson MJ, Price CP, Howick J. Point-of-care testing in UK primary care: a survey to establish clinical needs. Fam Pract. 2016;33(4):388-94. https://doi.org/10.1093/fampra/cmw018.

18. Cals J, van Weert H. Point-of-care tests in general practice: hope or hype? Eur J Gen Pract. 2013;19(4):251-6. https://doi. org/10.3109/13814788.2013.800041.

19. Yip PM, Venner AA, Shea J, Fuezery A, Huang Y, Massicotte L, Tetreault N, Tomalty C, Shaw JLV. Point-of-care testing: a position statement from the Canadian Society of Clinical Chemists. Clin Biochem. 2018;53:156-9. https://doi.org/10.1016/j.clinb iochem.2018.01.015.

20. Guidelines for point of care testing. National Pathology Accreditation Advisory Council, Commonwealth Department of Health, Australia. 2015. https://www.health.gov.au/internet/main/publi shing.nsf/Content/35DE5FC4786CBB33CA257EEB007C7B F2/\$File/Guidelines\%20PoCT\%201 st\%20Ed\%202015.pdf. Accessed 16 June 2019.

21. Position Statement: Point of Care Testing. Royal College of Pathologists of Australasia. 2016. https://www.rcpa.edu.au/getat tachment/49929780-7f4e-47ae-a78a-baec9955fc5e/Point-of-CareTesting.aspx. Accessed June 172019.

22. Sarraf E, Mathews DM, Tsai MH, Goodwin AJ. Optimizing the use of point of care testing devices for screening patients. J Clin Monit Comput. 2019. https://doi.org/10.1007/s10877-019-00332 -w.

23. Jacobson AK. Warfarin monitoring: point-of-care INR testing limitations and interpretation of the prothrombin time. J Thromb Thrombolysis. 2008;25(1):10-1. https://doi.org/10.1007/s1123 9-007-0098-5.

24. Hur M, Kim H, Park CM, La Gioia A, Choi SG, Choi JH, Moon HW, Yun YM. Comparison of international normalized ratio measurement between CoaguChek XS Plus and STA-R coagulation analyzers. Biomed Res Int. 2013;2013:213109. https://doi. org/10.1155/2013/213109.

25. Dimeski G, Morgan TJ, Presneill JJ, Venkatesh B. Disagreement between ion selective electrode direct and indirect sodium measurements: estimation of the problem in a tertiary referral hospital. J Crit Care. 2012;27(3):e326-e9. https://doi.org/10.1016/j. jerc.2011.11.003.

Publisher's Note Springer Nature remains neutral with regard to jurisdictional claims in published maps and institutional affiliations. 